\title{
Mycobacterium Bovis Characterization through RD4 Deletion and Spoligotyping Techniques
}

\author{
Yibrah Tekle ${ }^{1,3 *}$, Gezahegn Mamo $^{2}$ and Gobena Ameni ${ }^{2}$ \\ ${ }^{1}$ Raya University, Maichew, Ethiopia \\ ${ }^{2}$ Addis Ababa University, Bishoftu, Ethiopia \\ ${ }^{3}$ Harbin Veterinary Research Institute, China \\ *Corresponding author: Yibrah Tekle, Harbin Veterinary Research Institute, China
}

\section{ARTICLE INFO}

Received: 幽 January 03, 2020

Published: 幽 January 13, 2020

Citation: Yibrah Tekle, Gezahegn Mamo, Gobena Ameni. Mycobacterium Bovis Characterization through RD4 Deletion and Spoligotyping Techniques. Biomed J Sci \& Tech Res 24(4)-2020. BJSTR. MS.ID.004074.

Abbreviations: NTM: Nontuberculous Mycobacteria; MTBC: M. tuberculosis Complex; BTB: Bovine Tuberculosis; SNNPRs: Southern Nations Nationalities and Peoples Regional state

\section{ABSTRACT}

A cross sectional study was conducted on 753 Cattle which selected using systematic random sampling technique from December 2015 to May 2016 to isolate Mycobacterium bovis and its molecular characterization from cattle slaughtered at Hawassa University and Municipal abattoirs. The methods used were postmortem examination, bacteriological culturing, RD4 deletion typing and Spoligotyping. The overall prevalence of the bovine tuberculosis was 5.8\% (95\%CI: 4.17 8.52) on the basis of detailed postmortem examination. Out of 44 tissue samples cultured, 24 (54.5\%) were culture positive and all were acid fast staining positive. However, using RD4 deletion only three isolates were confirmed as Mycobacterium bovis. The further Spoligotyping characterizations of these three isolates revealed the strain SB1477. Most of the lesions were found in thoracic cavity lymph nodes $(75 \%)$, which indicated that respiratory route was the main mode of infection in the study area. Hence, the study confirmed that the low prevalence of BTB and the current Mycobacterium bovis strain circulate in the cattle population being SB1477. Therefore, further investigation needed including large study areas for epidemiological information on circulating strains, ways of transmission and molecular diversity of the $M$. bovis strains. further investigation at large area needed to have the current epidemiological data on the circulating strains, transmission and molecular diversity of the M. bovis.

Keywords: Bacteriological; Culturing; M. bovis; RD4 deletion; Spoligotyping; ZN Staining

\section{Introduction}

Mycobacteria are slow-growing, acid-fast and aerobic organisms whose genus classified in to more than 90 different species (Watterson 1998). A group of Mycobacterium species called $M$. tuberculosis Complex (MTBC) that comprise M. tuberculosis, M. bovis, M. microti and M. africanum, is of utmost clinical importance since it causes tuberculosis in humans worldwide [1]. Mycobacterium species other than those of the tuberculosis complex, also called Nontuberculous Mycobacteria (NTM), are widely distributed in the environment and may colonize and occasionally cause infections in humans [2-4]. Mycobacteria of the MTBC and NTM have been found to cause infections in immunecompetent and immunocompromised subjects and cause pathology in pulmonary and extrapulmonary sites [4-9]. Bovine Tuberculosis (BTB) is among the principal zoonotic diseases caused by $M$. bovis [10] which affects many vertebrate animals [11] and humans [12,13] and characterized by progressive development of granulomas/ tubercles in tissues and organs [14-16].

Bovine tuberculosis has been widely distributed throughout the world and has been recognized from 176 countries as one of the important bovine diseases causing great economic loss in animal production $[17,18]$ and the most frequent cause TB in man [19]. $M$. bovis is most frequently isolated from domesticated cattle [20-23], although recent studies indicated that $M$. tuberculosis has been isolated from cattle and M. bovis from humans infected with BTB and 
TB respectively. The members of MTBC are characterized by $99.9 \%$ or greater similarity at nucleotide level and are virtually identical at 16s rRNA sequence but they vary in host specificity. Bovine tuberculosis affects broad range of mammalian hosts including humans, cattle, deer, pigs, domestic cats, wild carnivores and omnivores [24]; it rarely affects equids or sheep [25]. Moreover, human TB of animal origin caused by $M$. bovis is becoming increasingly evident in developing countries [26,27]. The productivity efficiency of the infected animal reduced from 10-25\%; the direct losses due to the infection decreases in milk production $10-18 \%$ and meat production $15 \%$. BTB has both the effect in animal production and public health importance.

In developing countries like Ethiopia, the low standard living areas and socio-economic situation for both animals and humans are more contributing in TB transmission between human to human and human to cattle or vice versa [28]. Organisms are excreted in the exhaled air, in sputum, feces (from both intestinal lesions and swallowed sputum from pulmonary lesions), milk, urine, vaginal and uterine discharges, and discharges from open peripheral lymph nodes of infected animals [29,30]. Human infection by $M$. bovis is thought to be mainly through drinking of contaminated or unpasteurized raw milk. The potential for transmission of $M$. bovis and other mycobacteria between cattle and humans are the presence of close contact of animal and humans or the rural societies living together with their animals in the same microenvironment and house, raw milk and meat consumption habit, the prevalence of HIV increasing and HIV patient's susceptibility to TB [31]. In the areas where the bovine tuberculosis is common and the milk pasteurization is rare, M. bovis cases in human estimated $10-15 \%[32,33]$. Thus, in cattle the main route of infection transmission: aerosol, close contact between animals and ingestion of contaminated products [34-37].

Bovine tuberculosis, is an endemic disease of cattle in Ethiopia with prevalence of $1.1 \%-24.7 \%$ in abattoir and $3.5-50 \%$ in crossbreed farms, like human TB has not received more focus on research and its control strategies plus the test and slaughter control strategies not applied, due to its economic constraints, but its applicable effective method in developed countries. Due to inadequate comprehensive abattoir surveillance and lack of diagnostic facilities the BTB has limited information [38-40], particularly on genotypic characteristics of $M$. bovis, a strain affecting the cattle population in Ethiopia [41]. Knowing the M. bovis strains which are circulating in cattle population is using to examining host pathogen relationships to monitor transmission and spread of the disease among cattle [41-43]. Therefore, the object of this research paper was to isolated and molecular characterization of isolated Mycobacterium bovis using RD4 deletion typing and Spoligotyping techniques from the cattle slaughtered at Hawassa University and Municipal abattoirs, Southern Ethiopia.

\section{Materials and Methods}

\section{Study Area}

The study was conducted from December 2015 to May 2016 in Hawassa University and municipal abattoir in Southern Nations Nationalities and Peoples Regional state (SNNPRs), Southern Ethiopia. Hawassa city is located in Southern part of Ethiopia, in Sidama Zone, on the shores of Lake Hawassa in the Great Rift Valley and located $270 \mathrm{~km}$ South of Addis Ababa. The city serves as the capital of the SNNPRs, and its total area is 157.21 square kilometers. It bounded by Lake Hawassa on the West and Northwest, Chelelaka swampy area on the East and South-East, Tikur Wuha River on the North and Alamura Mountain on the South. It lies on the Trans-African Highway for Cairo-Cape Town and has a geographic coordinate of $7^{\circ} 3^{\prime} \mathrm{N}$ latitude and $38^{\circ} 28^{\prime} \mathrm{E}$ longitude and an elevation of 1708 . The livestock resource of the city is 61,123 cattle, 14,764 sheep, 17,735 goats, 5,544 equines and 56,961 poultry and the total population is estimated bout 304,479 .

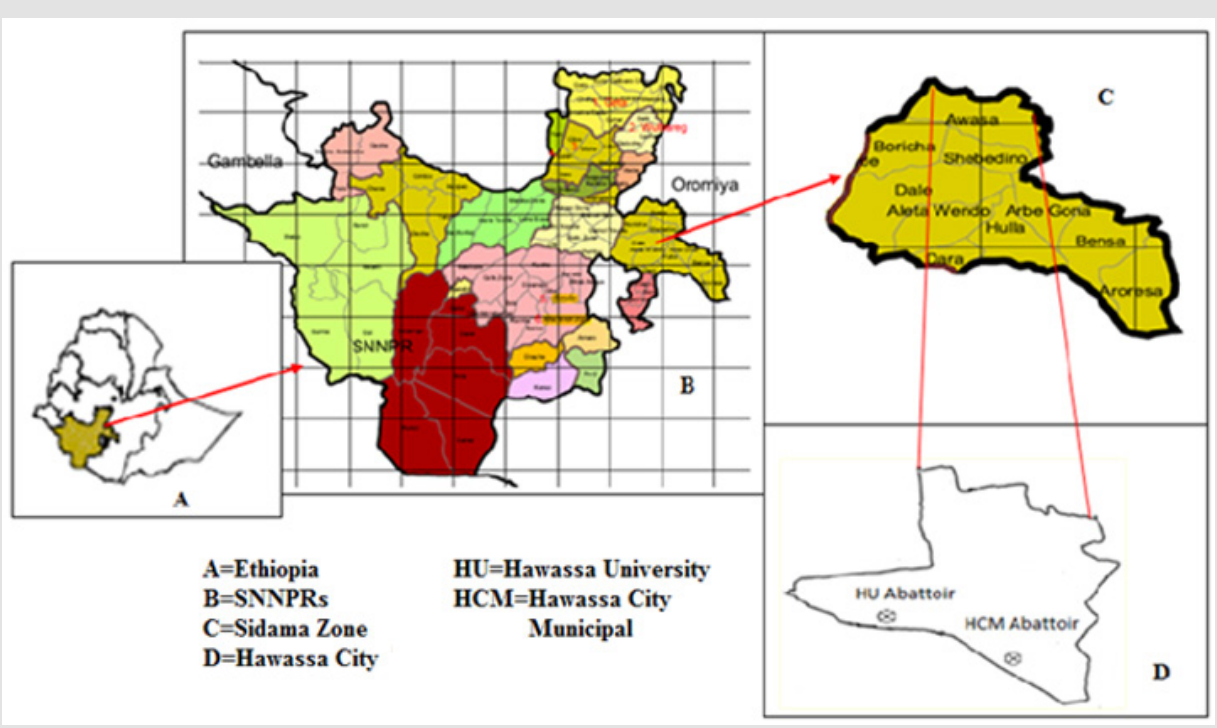

Figure 1: Geographical location map of Hawassa town. 
Hawassa city has two abattoirs: one municipality abattoir and second Hawassa University abattoir, in main campus. The Hawassa municipal abattoir supplies the inspected meat to about 304,479 inhabitants [44] and based on the information obtained from personnel working in Hawassa University Registrar Office, the University's abattoir supplies for about 25,000 students (personal communication). Even though the abattoirs were fenced, the places used to dispose condemned carcasses were not secured since they were easily accessed by hyenas, dogs and other animals. The overall hygiene and the internal facilities including the drainage were not good in the Municipal abattoir whereas the University's abattoir was good. Even though the Municipal abattoir has recently built abattoir inside the compound, currently the slaughtering is performing in the old house. The minimum and maximum numbers of cattle slaughtered per day during the study period in Hawassa city Municipal abattoir were about 75 and 175 heads of cattle, respectively and about 8 and 12 heads of cattle were for Hawassa University abattoir, respectively. Few numbers of female cattle were also slaughtered in both abattoirs which have reproductive problems, poor performance and at the end of their reproductive life (aged). The municipal abattoir was operated by one veterinarian and three assistant meat inspectors, but the University abattoir was operated only by one assistant meat inspector (Personal communication to the responsible bodies) (Figure 1).

\section{Study Animal}

A total of 753 apparently healthy adult cattle slaughtered in the abattoirs regardless of sex, breed and origin were considered in the study. The cattle used for this study were mainly originated from different markets; for the municipal abattoir were from Tula, Arsi Negele, Tukr Wuha, Wolayita, Harrar, Borena, Hawassa and Nazeriat (Adama) Markets and for University abattoir the origin was from Borena and Wolayita markets. All the study animals in this study were cross and local breed.

\section{Study Design and Sampling Method}

A cross sectional study with systematic random sampling was carried out to examine the carcass and sample suspected TB lesions from cattle slaughtered at Hawassa university and municipal abattoirs. Selection of cattle population to be involved in the study was based on systematic random sampling, from among those cattle slaughtered each day, which was arranged in a systematic manner with each individual animal constituting a sampling unit. In Hawassa city municipal abattoir on average 20 carcasses were decided to be inspected each day (range from 15 to 25) from among those slaughtered cattle whereas in Hawassa University abattoir the whole cattle slaughtered in each day were considered for postmortem examination because the number of slaughter cattle was often fewer (range from 6 to 12) compared the Hawassa city municipal abattoir. The work was carried out in all the weekdays except Wednesday and Friday when animals were not slaughtered due to fasting occasions according to the belief of Ethiopian Orthodox Christianity.

\section{Sample Size Determination}

All animals coming to the abattoirs from different markets during the study period were considered for sampling. The sample size calculation was done by using the Thrusfield formula:

$$
n=\frac{1.96^{2} \times p_{\text {exp }}\left(1-p_{\text {exp }}\right)}{d^{2}}
$$

Where

$\mathrm{n}=$ required sample size

$\mathrm{P}_{\text {exp }}=$ expected prevalence

$\mathrm{d}=$ desired absolute precision, $5 \%$

The expected prevalence of Hawassa city municipal abattoir was $(8.8 \%)$ used from the previous works of Biffa. The calculated sample size for the municipal abattoir was 123 heads of cattle, but to increase the precision of the study this sample size multiplied three times, then $n=369$ heads of cattle. Whereas the calculated sample size of the Hawassa University abattoir, $\mathrm{P}_{\exp }$ considered as $50 \%$ because there was no previous study on bovine tuberculosis in this abattoir, was 384 heads of cattle. Thereafter, the total animals supervised in both abattoirs were 753 heads of cattle.

\section{Study Methodologies}

Postmortem Examination: Postmortem examination had carried us according to the OIE and Meat Inspection and Quarantine Division of the Ministry of Agriculture method [45]. All lymph nodes, livers, kidney and lungs were visualized, palpated, and incised into a size of $2 \mathrm{~mm}$ to facilitate the detection of tuberculous lesion from each animal. These include the mandibular, medial retropharyngeal, cranial and caudal mediastinal, left and right bronchial, hepatic, mesenteric lymph nodes as well as the seven lobes of the two lungs, including the left apical, left cardiac, left diaphragmatic, right apical, right cardiac, right diaphragmatic and right accessory lobes were investigated. The animal was classified as suspected tuberculosis lesion when tuberculous lesion was found, and if not as non-lesioned.

The cut surfaces were examined under bright light for the presence of abscess, cheesy mass, and tubercles [46]. In the presence of suspected tuberculous lesion, tissue samples were collected independently in sterile universal bottles containing $0.85 \%$ normal saline for culture and kept store froze at -200c at Hawassa University, School of Animal Science and Rang Management, Dairy section before being transporting to laboratory. The samples were labeled and pooled together and then transported at $4^{\circ} \mathrm{C}$ under cold chain by ice box with packed ice to Addis Ababa University, College of Veterinary Medicine and Agricultural (CVMA) and stored at -200c until bacteriological culture. 
Mycobacteria Culturing and Acid-Fast Staining: For bacteriological culture, tissue samples were macerated in sterile mortal by using surgical blades and forceps to get fine pieces and in order to initiate the release of mycobacteria organisms from body fluid and cells and then homogenized by pestle and mortar. Five milliliters of the homogenized tissue sample were transferred into centrifuge tube and decontaminated with equal volume $4 \%$ $\mathrm{NaOH}$ followed by centrifugation at 3,000 rpm for 15 minutes. The supernatant was discarded, while the sediment was neutralized with $1 \%(0.1 \mathrm{~N}) \mathrm{HCl}$ using phenol as an indicator. Neutralization achieved when the color of the solution changed from purple to yellow [47]. Thereafter, $0.1 \mathrm{ml}$ of the suspension from each sample was inoculated on to LJ egg-based media. Duplicates of LJ media were used; one enriched with sodium pyruvate, while the other was enriched with glycerol. The Cultures were incubated at $37^{\circ} \mathrm{C}$ for 1 week and in upright position for the rest 8-12 weeks.

The media was in tightly closed tubes to avoid desiccation and slopes were examined for macroscopic growth at intervals during the incubation period for the presence of any mycobacterial colonies [47]. Whenever, colonies were seen, ZN staining was performed to confirm the presence of Acid-fast bacilli [48-50]. In parallel to the ZN staining, Positive colonies were preserved with freezing media, and some portion of the colonies were heat killed in water bath maintained at $800 \mathrm{C}$ heat for 45 minutes, by mixing two

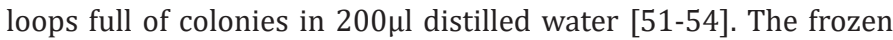
and heat killed isolates were stored at -20 0C for future Mycobacteriology and further molecular typing analysis was performed at Akililu Lemma Institute of Pathobiology according to the standard developed by [54-59].

Region of Difference (RD)-4 Deletion Typing: For the RD4 deletion typing, the procedure described by Cadmus was used. Each sample was tested in a separate PCR tube. Primers directed against the RD4 were used to generate a deletion profile that would allow species identification of the isolate. RD4 is $12.7 \mathrm{~kb}$ genetic segment that is deleted from M. bovis BCG strain, but present in M. microti, $M$. africanum and M. tuberculosis [55]. RD4 internal F: 5'-ACA CGC TGG CGA AGT ATA GC-3'; RD4 flank R: 5'-AAG GCG AAC AGA TTC AGC AT-3' and RD4 flank F: 5'-CTC GTC GAA GGC CAC TAA AG-3' primers were used to check for the presence of RD4 locus. Each PCR tube consisted of $7 \mu$ l distilled water (Qiagen), $10 \mu$ l Hot Star Taq Master Mix, $0.3 \mu$ of each of the three primers and $2.1 \mu \mathrm{l}$ of DNA template, thus making the total final volume of $20 \mu \mathrm{l}$. M. tuberculosis $\mathrm{H} 37 \mathrm{Rv}$ and $M$. bovis SB1176 were used as positive control, and distilled water was used as a negative control. The mixture was heated in a Thermal Cycler (VWR, International Ltd. Portsmouth, UK ) using an initial hot start at $95^{\circ} \mathrm{C}$ for 15 minutes and then subjected to 35 cycles of $95^{\circ} \mathrm{C}$ for 1 minute, $55^{\circ} \mathrm{C}$ for 1 minute, $72^{\circ} \mathrm{C}$ for 1 minute and final extension step $72^{\circ} \mathrm{C}$ for 10 minutes to complete the cycle. The product was electrophoresed in 1.5\% agarose gel in $1 \mathrm{x}$ TAE running buffer; SYBR Safe/Ethidium bromide at a ratio of 1:10, $100 \mathrm{bp}$ DNA ladder and orange $6 \mathrm{x}$ loading dye were used in gel electrophoresis.
The gel was visualized using Syngene Bio Imaging System (Syoptics Group). Interpretation of the result was based on the detection of bands of different sizes. The presence of RD4 (RD4 is intact in $M$. tuberculosis, M. africanum) gives a product size of $335 \mathrm{bp}$ (RD4 intF + RD4flankR), and its absence (M. bovis) gives a product size of 446 bp (RD4flankF + RD4flankR).

Spoligotyping: Spoligotyping was carried out using the commercially available kit according to the manufacturer's instructions and as previously described by Kamerbeek. Briefly, the direct repeat (DR) region was amplified with primers DRa (5'-GGT TTT GGG TCT GAC GAC - 3 ' biotinylated at the $5^{\prime}$ end) and DRb (5'CCG AGA GGG GAC GGA AAC - $3^{\prime}$ ). PCR amplification was done for 30 cycles with denaturation and annealing for $1 \mathrm{~min}$ at $95^{\circ} \mathrm{C}$ and $1 \mathrm{~min}$ at $55^{\circ} \mathrm{C}$, respectively, and extension for $30 \mathrm{~s}$ at $72^{\circ} \mathrm{C}$ in each cycle. The amplified DNA was hybridized to inter-DR spacer oligonucleotides covalently bound to a membrane for 1 hour at $60^{\circ} \mathrm{C}$. Reference strains of M. tuberculosis (H37Rv) and M. bovis SB1176 were used as positive control whereas sterile water was used as a negative control. The amplified DNA was subsequently hybridized to a set of 43 oligonucleotide probes by reverse line blotting. The hybridized PCR products were incubated with streptavidin peroxidase conjugate and the signal detection was done with an enhanced chemiluminescence detection system followed by exposure to an $\mathrm{X}$-ray film according to the manufacturer's instructions. The X-ray film was developed and washed using standard photochemical procedures. The results were entered in a computer-based strain identification system described in international online database website http://www.mbovis.org.

Statistical Analysis: Prevalence was calculated as the proportion of suspected lesion positive animals from the total number of animals sampled [60]. Presence or absence of TB like lesions and affected tissues (suspected lesions) were recorded during postmortem examination. The recorded data was entered and stored using Microsoft Excel computer program. In molecular epidemiology study of isolates from animal tissues, the spoligotype patterns were converted in to binary and entered to the online Spoligotyping database website http://www.mbovis.org. to retrieved the strain type.

\section{Results}

\section{Distribution of Gross Pathological Lesions and Prevalence}

The overall prevalence of BTB was 5.84\% (95\%CI: 4.58 8.42), upon detailed postmortem examination of 753 cattle. Gross pathological lesions were observed in lymph nodes and organs of the slaughtered cattle; the majority of the lesions were considered typical of tuberculous lesions which characterized by central round, oval, or irregular, often coalescing areas of caseous necrosis and mineralization (calcification) (Figure 2). Large encapsulated nodules containing thick yellowish cheesy material were mostly 
observed in the thoracic lymph nodes. Whenever gross lesions of suggestive pathological lesions of TB noticed in any tissue; the tissue was classified as positive for TB. According to the anatomical site, $75 \%$ (33/44) of the gross lesions were sampled from thoracic cavity followed by abdomen cavity and head region $13.64 \%(6 / 44)$ and $15.91 \%$ (5/44) respectively. $70.45 \%$ (31/44) of the gross lesions were collected from Mediastinal lymph nodes whereas only $11.36 \%$ (5/44) where obtained from mesenteric lymph nodes (Table 1).
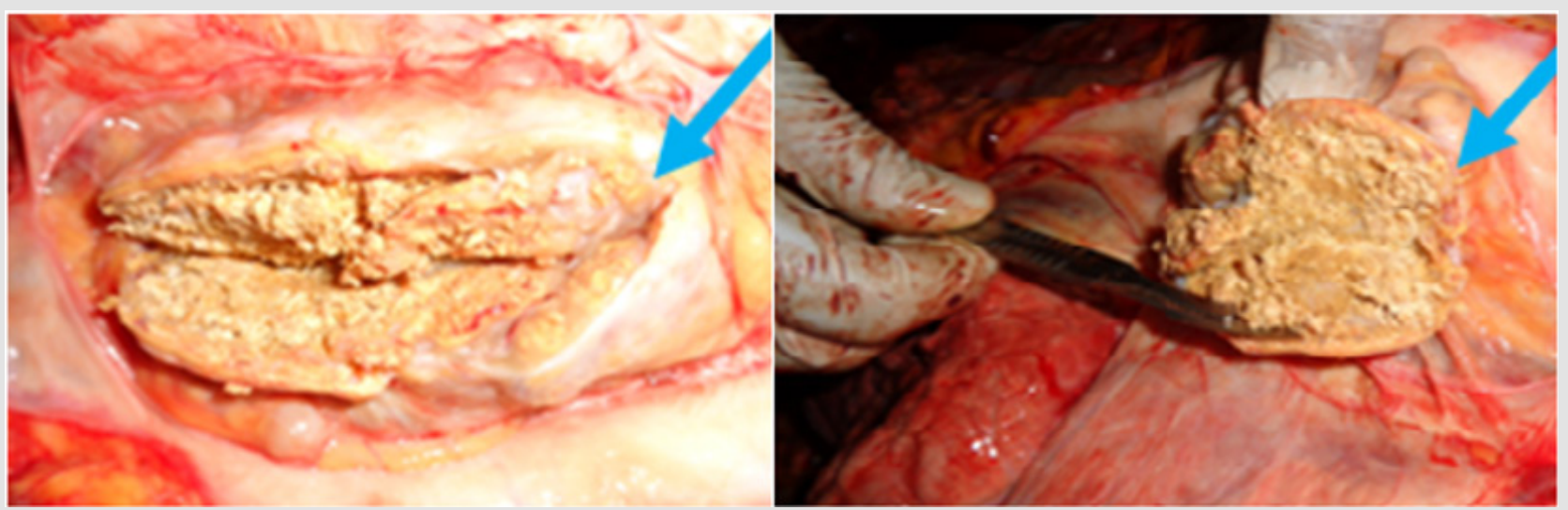

Figure 2: The typical TB lesions of cattle slaughtered in Hawassa abattoirs (Calcified, Caseous and Necrotic Granulomatous lesions in mediastinum lymph nodes, indicated by arrow).

Table 1: Lesion distribution in different organs and anatomic parts.

\begin{tabular}{|c|c|c|c|}
\hline Anatomical Site & Affected organs & Frequency (\%) & Total (\%) \\
\hline \multirow{2}{*}{ Head } & Retropharyngeal LN & $4(9.09 \%)$ & $6(13.64 \%)$ \\
\cline { 2 - 4 } & Mandibular LN & $2(4.5 \%)$ & $33(75 \%)$ \\
\hline Thorax & Mediastinal LN & $31(70.45 \%)$ & $7(15.91 \%)$ \\
\hline Abdomen & Mesenteric LN & $5(11.36 \%)$ & \\
\hline & Livers & $2(4.55 \%)$ & $44(100 \%)$ \\
\hline
\end{tabular}

\section{Mycobacteriological Culture and Acid-Fast Stain Results}

Out of the total 44 suspected BTB lesions Mycobacteriological cultured; growth was observed in $24(54.55 \%)$ tissue samples on LJ medium culture (Figure 3 ) and all of them were found to be AFB positive. From this growth, colonies collected at a higher frequency from pyruvate supplemented LJ medium, 12/24(50\%) than glycerol supplemented LJ medium, 8/24 (33.33\%) and the remained $16.77 \%$ (4/24) from both LJ medium (Table 2). The observed colony morphology was smooth whitish or yellowish color colony (Table 3). These colonies positive for the ZN staining were cocci, short and long rod shape and also found in single and clump (Figure 4).

Table 2: Mycobacteriological culture result from suspected TB lesion on LJ medium and ZN staining positivity.

\begin{tabular}{|c|c|c|c|c|c|c|}
\hline \multirow{2}{*}{ Abattoirs } & \multirow{2}{*}{ No. of Sampled } & \multirow{2}{*}{ Lesions (\%) } & \multicolumn{3}{|c|}{ Growth on LJ medium } & \multirow{2}{*}{ ZN stain positive $(\%)$} \\
\hline & & & LJP & LJG & Both & \\
\hline Hawassa University Abattoir & 384 & $31(8.07)$ & 9 & 6 & 2 & $17(70.83)$ \\
\hline Hawassa City Municipal Abattoir & 369 & $13(3.51)$ & 2 & 3 & 2 & $7(29.17)$ \\
\hline Total & 753 & $44(5.84)$ & 11 & 9 & 4 & $24(100)$ \\
\hline
\end{tabular}

Table 3: Time appearance of mycobacteria colony growth on the LJ medium and characteristics.

\begin{tabular}{|c|c|c|c|c|}
\hline \multirow{2}{*}{ No of Isolates } & \multirow{2}{*}{ Source } & \multicolumn{2}{|c|}{ Time to appear in week } & \multirow{2}{*}{ CoG } \\
\cline { 2 - 4 } & & LJP & & Pinpoint, smooth, whitish, yellowish characteristics \\
\hline 5 & Cattle & 3 & 5 & Pinpoint, smooth, whitish, yellowish \\
\hline 13 & Cattle & 4 & 6 & Pinpoint, smooth, whitish, yellowish \\
\hline 6 & Cattle & & 6
\end{tabular}




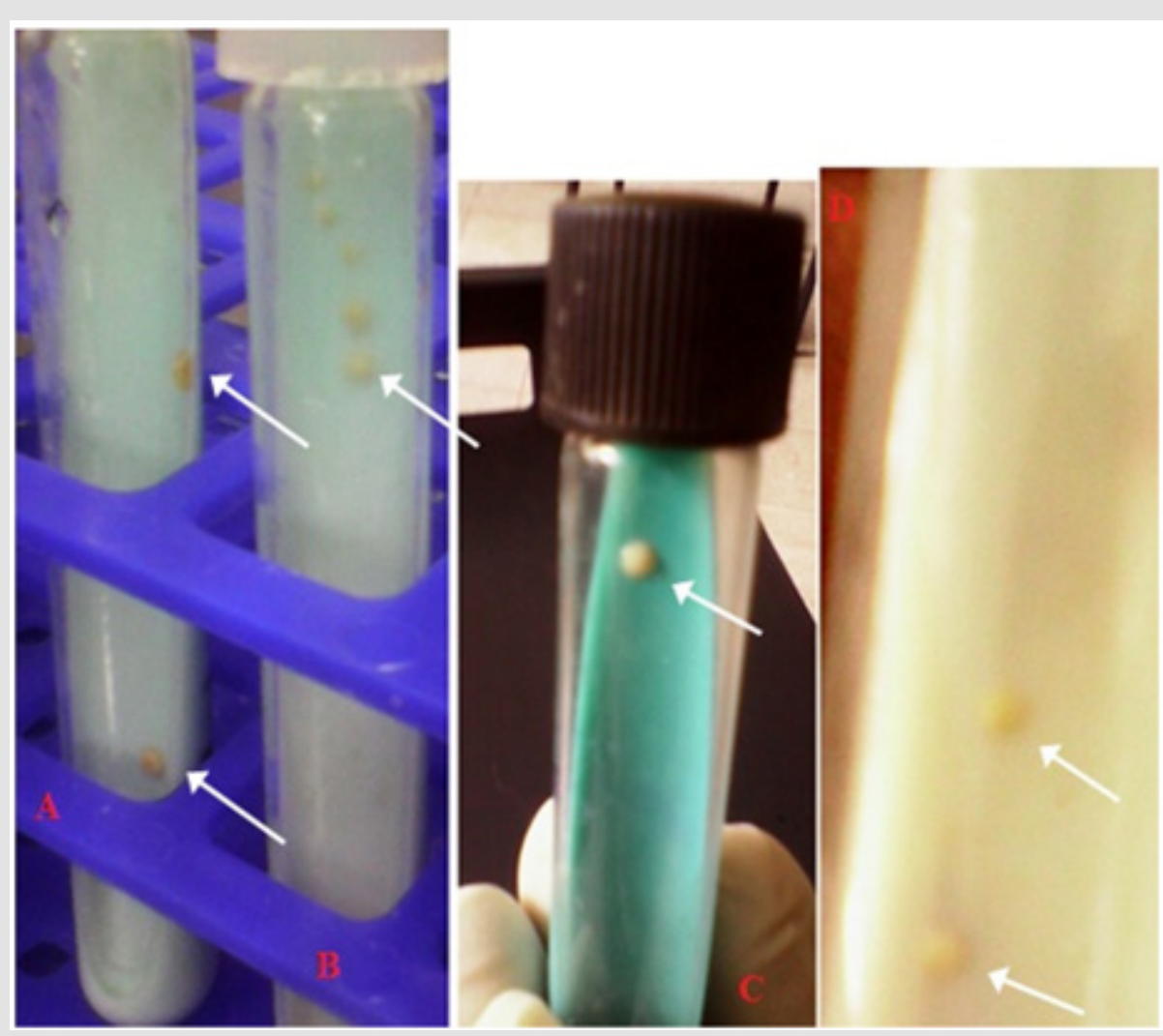

Figure 3: (A \& C) Colonies grown on LJ medium glycerol supplemented (B\&D) LJ medium pyruvate supplemented (Arrows indicate the colonies growth which are smooth, whitish or yellowish in color).
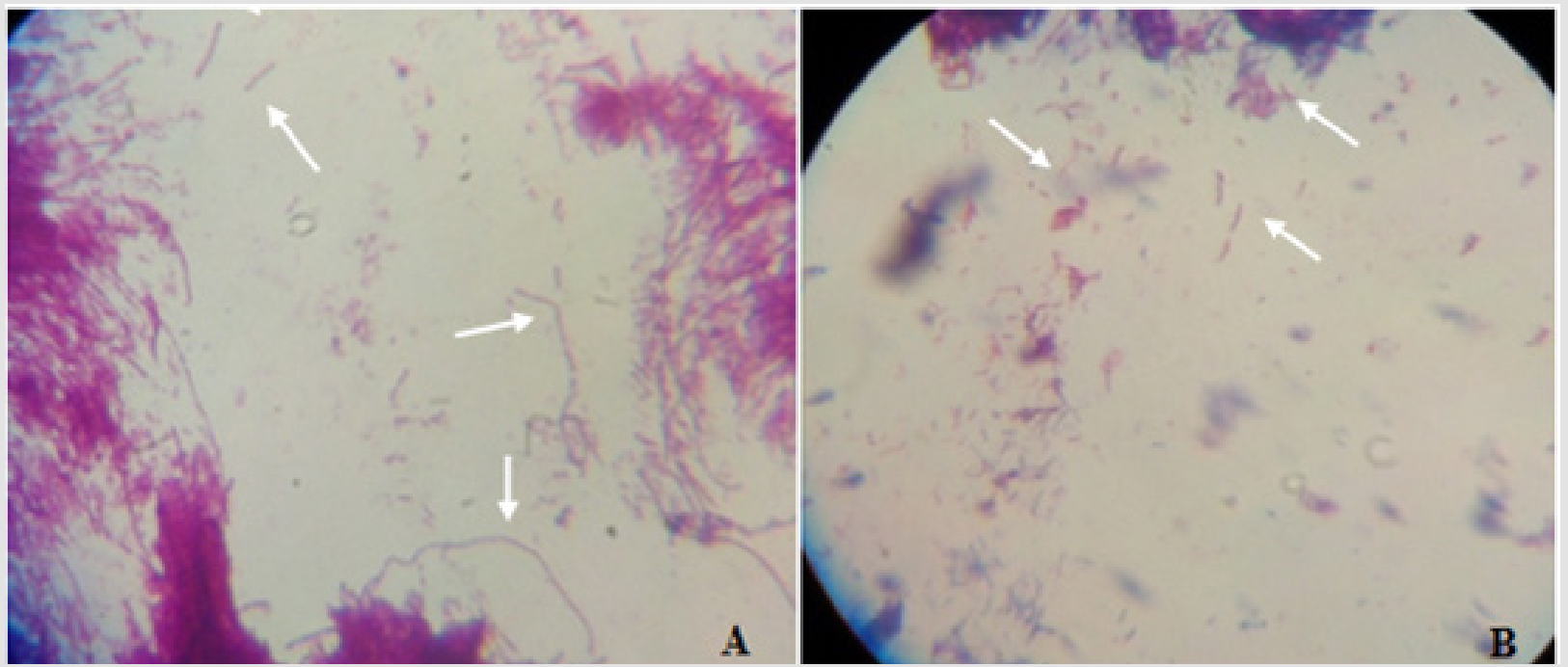

Figure 4: Acid fast bacilli staining positive isolates from mycobacteriological culture colony grows from lymph nodes TB lesion (arrows indicate acid fast bacilli which a short and long, in single or clump).

\section{Molecular Characterization of Mycobacteria Isolates}

The RD4 deletion typing of isolates was confirmed only three isolates to be $M$. bovis (Figure 5) that indicated a product size of $446 \mathrm{bp}$; the rest of 21 isolates did not show any signal in RD4 deletion typing the Spoligotyping of the three $M$. bovis isolates, which were positive in RD4 deletion, showed the typical M. bovis Spoligotyping pattern with similar pattern and based on the database website http://www.mbovis.org analysis of the Spoligotyping results isolates were identified as SB1477 (Figure 6). 


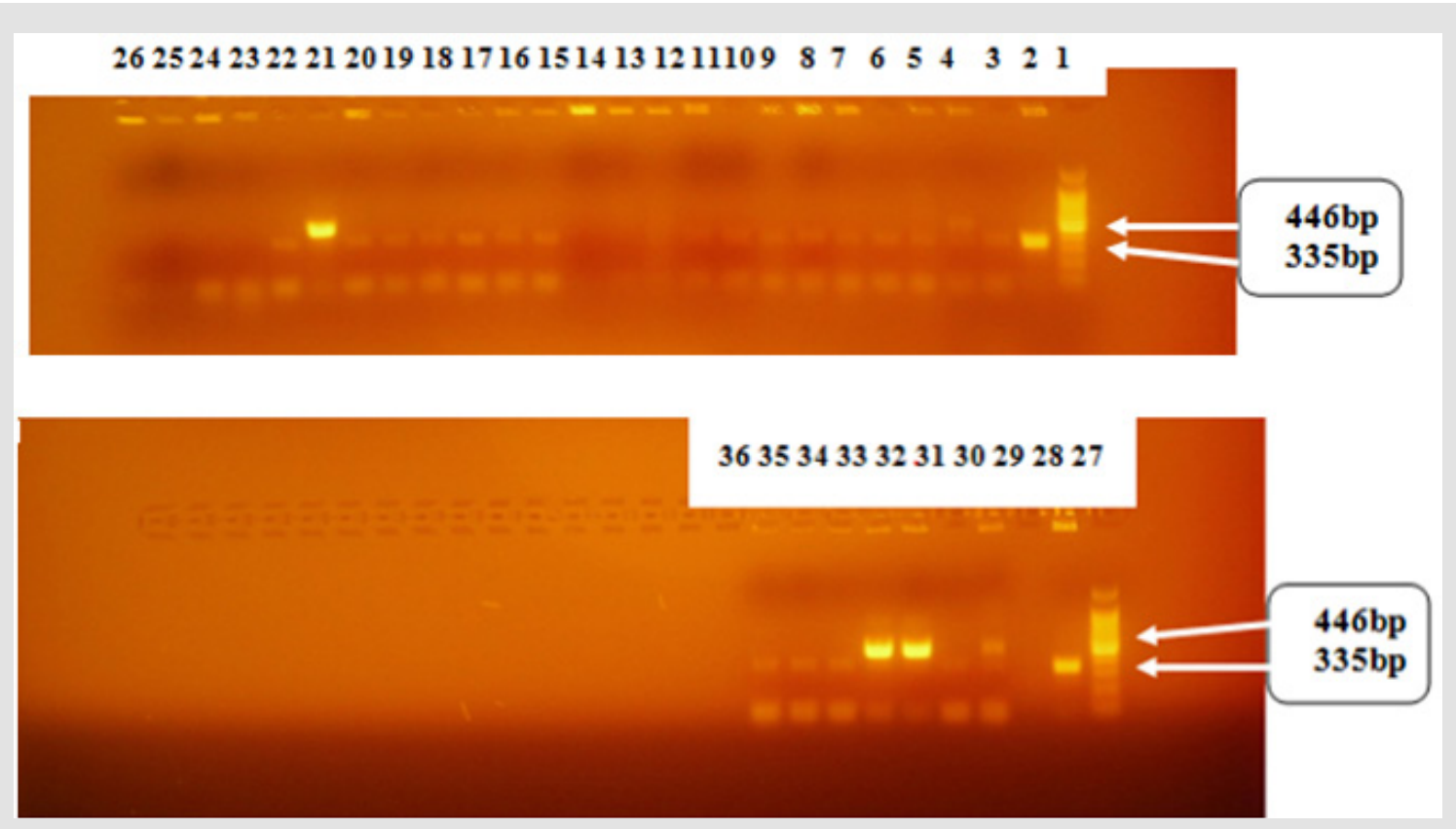

Figure 5: Electrophoretic separation of PCR products by RD4 deletion typing of mycobacteria isolates from 24 isolates sampled culture. Lane 1 and 27- Ladder (100bp), Lane 2 and 28- M. tuberculosis H37Rv positive control, Lane 3 and 29- Distiled water negative control, Lane 4 and 30- M. bovis SB1176 positive control, Lane 5-26 and 31- 36 isolates from tissue culture positives, Lane 21, 32 and 33 positive for M. bovis and Lane 5-20, 22-26,31,34-36 were negative for M. bovis.

\begin{tabular}{|c|c|c|}
\hline Code & Strain & Binary Format \\
\hline $\begin{array}{l}\text { Positive control } \\
\text { (M. bovis) }\end{array}$ & SB1176 & \\
\hline $\begin{array}{l}\text { Negative control } \\
\text { (distil water) }\end{array}$ & & \\
\hline HAp 39 & SB1477 & 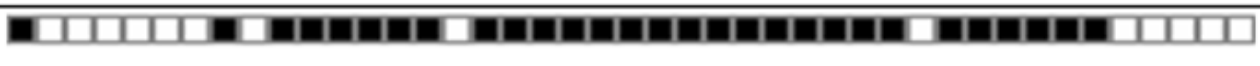 \\
\hline H41Med & SB1477 & 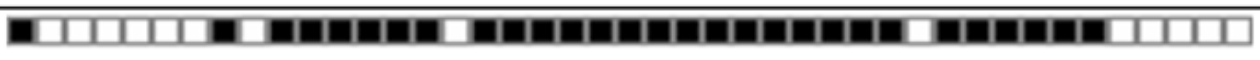 \\
\hline H39 Med & SB1477 & 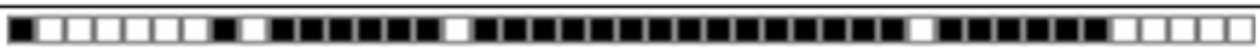 \\
\hline
\end{tabular}

Figure 6: Spoligotype patterns of M. bovis isolates from TB lesions of cattle from Hawassa abattoirs. The filled boxes (blacks) represent the presence of spacers and the empty boxes (white) represent the absence of spacers. AP39. H41Med and H39Med are isolates from sample.

\section{Discussion}

Bovine tuberculosis is a chronic infectious disease of animals characterized by the formation of granulomas in tissues and its detection is carried out most commonly on the basis of tuberculin skin testing, abattoir meat inspection and rarely on bacteriological techniques. Bovine tuberculosis has serious economic significance to the livestock sector and public health hazard to human. Tuberculosis caused by $M$. bovis is clinically indistinguishable from tuberculosis caused by M. tuberculosis and the proportion of human tuberculosis caused by $M$. bovis is estimated to 10-
$15 \%$ [61-63]. In the present study, upon detailed post mortem examination of 753 cattle an overall prevalence of BTB was $5.84 \%$ (95\%CI: 4.58 - 8.42) which is comparably in agreement with the findings of various researchers who reported prevalence of BTB $4.2 \%$ in Yabello municipal [64], 4.5\% in Hosaana abattoir [65], $5.16 \%$ in Adama Municipality abattoir [66,67], 5.1\% in Nekemte Municipality abattoir [68], 5\% in Kombolch ELFORA abattoir [69], 6.4\% in Mekelle town municipal abattoir [70] and 6.79\% in Adama municipal abattoir [71] as well as it was the same (5.8\%) with research report of Romha in western Tigray Zone. However, the total prevalence of this study was lower than previous studies 
carried out by other authors; $11.50 \%$ by Abdurohaman in Butajira, 9\% [72] in Butajira abattoir, $8.8 \%$ by Biffa in Hawassa municipal abattoir, $7.96 \%$ by Regassa (1999) in Wolayta, Southern Ethiopia and $24.7 \%$ [73] in Adama municipal abattoir.

On the other hand, the finding of this study was higher than the results of Regassa in Hawassa municipal abattoir (1.1\%), Gebremedhin in Dilla Municipal Abattoir (2.6\%), Asseged in Addis Ababa (1.48\%) and Shitaye in Addis Ababa (3.46\%). This lower prevalence recorded in the present study could be due to the fact that animals slaughtered in the abattoirs were mainly local breeds (Zebu) (675 out of 753) which are relatively resistant to BTB [74]. This the variations in prevalence could be due to the possible difference in the epidemiology of the disease in the animal populations, markets sources of animal (from which they brought to abattoirs either from high BTB prevalent or their local BTB burden), body condition score of the animals and types of production system; The intensive livestock management system could contribute the development of mycobacterial infections than the extensive livestock management system [75-78]. Based on the postmortem inspection, the prevalence of TB lesions showed marked variation between the two abattoirs; the cases recorded in cattle slaughtered in Hawassa university abattoir was higher, 8.1\% (31/384) than Hawassa municipal abattoir, 3.5\% (13/369). Because most of the animal slaughtered at Hawassa University abattoir were from Boren area which might show the high prevalence in the source [79]. The abattoirs have no effects in the development of the TB infection within that short period of time since TB is a chronic disease that needs long period of time.

The best evidence of the transmission route of M. bovis to cattle is the pattern of lesions observed in slaughtered animals [80]. In the present study, gross tuberculous lesions were found most frequently in lymph nodes of the thoracic cavity, 75\% (33/44); followed by the lymph nodes of the head region, $13.64 \%(6 / 44)$ and the lymph nodes of the abdominal cavity $11.36 \%(5 / 44)$. The occurrence of tuberculous lesions in thoracic cavity was lower than the results of previous studies which reported greater than $84 \%$ TB lesions occurrence in the respiratory system [8185]; whereas it was higher than the report of Dechassa (67.7\%), Firdessa (70\%), Miliano-suazo (49.2\%) and Regassa (50\%). As a result, this study indicated the main route of transmission and infection being respiratory route and this finding agreed with the previous researchers who reported the same route of transmission and infection, respiratory route [86-90]. In the current study, the growth rate of mycobacteria on culture media was 54.5\% (24/44). M. bovis grows poorly on standard LJ medium [91]. Furthermore, the presence of caseous and/or calcified lesions and miscategorization of tuberculous lesions resembling nontuberculous lesions as tuberculous lesions may not always found to be of mycobacterial origin; viable mycobacteria may not be present in calcified lesions.

However, the result of this study, $54.5 \%$, was higher than the previous report (47\%) of Ameni, (23.6\%) Araujo, (32\%) Shimeles,
(35\%) Müller and (31.4\%) [51] culture positivity from the lesion positive samples; but this finding was found slightly the same with the report of (56\%). RD4 deletion typing of the isolates from 24 animal tissue samples; only three isolates were confirmed to be M. bovis indicating product size of $446 \mathrm{bp}$ while the remained isolates were not showed any signal in RD4. Further molecular characterization using Spoligotyping on the three M. bovis isolate has designated the isolates as strain SB1477. The outcome was revealed the same Spoligotyping patterns (clustered stating) were recognized among these $M$. bovis isolates and defined as of type SB1477 at the international Spoligotyping database www.mbovis. org. This Spoligotyping pattern of the strains has similarities to the strains previously described in Addis Ababa farm, Ethiopia. This similar spoligopattern show that the strain has been circulating and transmitting in the cattle population of Borna and wolayta area. Warrants further investigation on their epidemiological and zoontic role in the area.

\section{Conclusion}

The output of this study has indicated that an overall BTB prevalence of $5.8 \%$ of which $8.1 \%$ and $3.5 \%$ was found at Hawassa University abattoir and Hawassa municipal abattoir respectively. This could be indicating the presence of BTB infection in certain geographical areas. This research also revealed that the respiratory route was the major means of BTB transmission among the cattle population. The isolation and molecular characterization of this study confirmed that the clustered $M$. bovis strains (SB1477) circulating in the cattle population of the study area. In conclusion, in this study Gross pathological lesions, bacteriological culture, ZN staining and the molecular characterization findings indicated the occurrence of BTB in apparently healthy cattle in the study area and $M$. bovis has been confirmed as a causative agent of BTB with moderately low prevalence, a threat to livestock production and also for public health.

Basis of findings the present study the following points are recommended:

a) Further investigation needed by involving large study areas for epidemiological information on circulating strains, ways of transmission and molecular diversity of the M. bovis strains.

b) It's also better genus typing molecular characterization of the pathological lesion /isolates to identifying the presence of nontuberculousis mycobacterium and mycobacterium tuberculosis complex in the study area.

c) BTB control strategies should be designed to reduce the occurrence of BTB in livestock of Southern Region in particular and in Ethiopia in general.

d) A proper postmortem meat inspection should be practiced efficiently in the abattoirs before taking beef to the retail markets to reduce the public health risk. 


\section{Acknowledgement}

This research was done under the Thematic Research Project of "Mycobacterial Infection in Selected Rural Communities of Ethiopia and their Animals," a collaborative research between College of Veterinary Medicine and Agriculture and Aklilu Lemma Institute of Pathobiology and funded by the Addis Ababa University Research and Technology Transfer office and I am thankful for the financial support obtained from the project.

Our Appreciation is run to all staff members of tuberculosis laboratory of the Institute of Aklilu Lemma Pathobiology for their genuine and cooperativeness during the laboratory work, especially Mr. Samuel Tolasa and Mr.Aboma Zewude. We are grateful to acknowledge Hawassa University, the staff of Faculty Veterinary Medicine, Faculty of Animal and Range Management Science, Dairy Section and Hawassa University Slaughter House staff (particularly Mr. Abera Elias and W/o Emebet Abera) as well as our thank go to the staff of Hawassa city municipal abattoir specially Mr. Tarekegn Birhanu, Mr. Abera Sintayohu, Mr. Betiso Chuko and Dr. Eshetu Belayneh.

\section{References}

1. Abdurohaman M (2009) Cross sectional study of bovine tuberculosis in Butajira municipal abattoir, South West Ethiopia. J Global Vet 6: 172-179.

2. Adle Biassette H, Huerre M, Breton G, Ruimy R, Carbonnelle A, et al. (2003) Nontuberculous mycobacterial diseases. Ann Pathol 23: 216235.

3. Amanfu W (2006) The situation of tuberculosis and tuberculosis in animal of economic interest. Tuberculosis 86(3-4): 330-335.

4. Ameni G, Wudie A (2003) Preliminary study on bovine tuberculosis in Nazareth municipality abattoir of central Ethiopia. B Anim Health Pro Afr 51: 25-132.

5. Ameni G, Aseffa A, Engers H, Young D, Hewinson G, et al. (2006) Cattle husbandry in Ethiopia is a predominant factor for affecting the pathology of bovine tuberculosis and gamma interferon response to mycobacterial antigens. Clin Vaccine Immunol 13(9): 1030-1036.

6. Ameni G, Aseffa A, Engers H, Young D, Gordon S, et al. (2007) High prevalence and increased severity of pathology of bovine tuberculosis in Holsteins compared to zebu breeds under field cattle husbandry in Central Ethiopia. Clin Vaccine Immunol 14(10): 1356-1361.

7. Ameni G, Desta F, Firdessa R (2010) Molecular typing of Mycobacterium bovis isolated from tuberculosis lesions of cattle in north eastern Ethiopia. Vet Rec 167(4): 138-141.

8. Araujo CP, Leite CQ, Prince KA, Jorge KS, Osorio AL, et al. (2005) Mycobacterium bovis identification by a molecular method from postmortem inspected cattle obtained in abattoirs of Mato Grosso do Sul, Brazil. The Memórias do Instituto Oswaldo Cruz 100(7): 749-752.

9. Ashford DA, Whitney E, Raghunathan P, Cosivi O (2001) Epidemiology of selected mycobacteria that infect humans and other animals. Scientific and Technical Review OIE 20(1): 325-337.

10. Asseged B, Lubke Beeke A, Lemma E, Tadele K, Britton S (2000) Bovine tuberculosis: a cross-sectional and epidemiological study in and around Addis ababa. B Anim Health Pro Afr 48: 71-80.

11. Asseged B, Woldesenbet Z, Yimer E, Lemma E (2004) Evaluation of abattoir inspection for the diagnosis of Mycobacterium bovis infection in cattle at Addis Ababa abattoir. Trop Anim Health Pro 36(6): 537-546.
12. Awah Ndukum J, Kudi AC, Bradley G, Ane Anyangwe IP, Titanji VK, et al. (2012) Prevalence of bovine tuberculosis in cattle in the highlands of Cameroon based on the detection of lesions in slaughtered cattle and tuberculin skin tests of live cattle. Vet Med 57: 59-76.

13. Ayele WY, Neill SD, Zinsstag J, Weiss MG, Pavlik I (2004) Bovine tuberculosis: an old disease but a new threat to Africa. Int J Tubercle Lung D 8(8): 924-937.

14. Barne A, Rojo S, Moretto H (2004) Prevalence of mycobacteriosis and tuberculosis in a reference hospital, Cordoba province. Rev Arg Microbiol 36(4): 170-173.

15. Berg S, Firdessa R, Habtamu M, Gadisa E, Mengistu A, et al. (2009) The burden of mycobacterial disease in Ethiopian cattle: implications for public health. PLoS ONE 4(4): 50-68.

16. Berg S, Garcia Pelayo MC, Muller B, Hailu E, Asiimwe B, et al. (2011) African 2, a clonal complex of Mycobacterium bovis epidemiologically important in East Africa. J Bacteriol 193(3): 670-678.

17. Biffa D, Inangolet F, Oloya J, Asseged B, Badaso M, et al. (2009) Prevalence of bovine tuberculosis in Ethiopian slaughter cattle based on postmortem examination. Trop Anim Health Pro 41(5): 755-765.

18. Biffa D, Asseged B, Eystein S (2010) Diagnostic efficiency of abattoir meat inspection service in Ethiopia to detect carcasses infected with Mycobacterium bovis: Implications for public health. BMC Public Health 6(10): 462.

19. Biffa D, Skjerve E, Oloya J, Bogale A, Abebe F, et al. (2010) Molecular characterization of Mycobacterium bovis isolates from Ethiopian cattle. BMC Vet Res 6: 28.

20. Brosch R, Gordon S, Marmiesse M, Brodin P, Buchrieser C, et al. (2002) A new evolutionary scenario for the Mycobacterium tuberculosis complex. P Natl Acad Sci USA 99(6): 3684-3689.

21. Buncic S (2006) Integrated Food Safety and Veterinary Public Health. 1sted CABI London UK 61.

22. Cadmus S, Palmer S, Okker M, Dale J, Gover K, et al. (2006) Molecular analysis of human and bovine tubercle bacilli from a local setting in Nigeria. J Clin Microbiol 44(1): 29-34.

23. Castro CM, Puerto G, García LM, Orjuela DL, Polo CL, et al. (2007) Molecular identification of non-tuberculous mycobacteria. Biomed 27: 439-446.

24. Chukwu ID, Chukwu CO, Kandakai Olukemi YT, Owolodun O, Nwosuh C et al. (2013) Detection of Mycobacterium tuberculosis Complex in Lung Specimen of Slaughtered Cattle and Goats by a DNA Based multiplex Polymerase Chain Reaction and Ziehl-Neelsen Methods In Jos, Nigeria. Brit Mic Res J 3(4): 550-556.

25. Cleaveland S, Shaw DJ, Mfinanga SG, Shirima G, Kazwala RR, et al. (2007) Mycobacterium bovis in rural Tanzania: risk factors for infection in human and cattle populations. Tuberculosis 87(1): 30-43.

26. Collins JD (1996) Factors relevant to M. bovis eradication. Irsh Vet J 49: 241-243.

27. Corner LA, Moville L, McCubbin K, Small KI, McCormick BS, et al. (1990) Efficacy of inspection procedures for detection of tuberculous lesions in cattle. Aust Vet J 67(11): 338-392.

28. Cosivi O, Meslin FK, Dabron CJ, Raviglione MC, Fujikura T, et al. (1998) Zoonotic tuberculosis due to M. bovis in developing countries. Emerg inf Dis 4(1): 59-70.

29. (2007) The 2007 Population and Housing Census of Ethiopia. Addis Ababa Ethiopia

30. (2010/2011) Agricultural sample survey, volume II report on livestock and livestock characteristics (private peasant holdings). Federal Democratic Republic of Ethiopia 90. 
31. Dechassa T (2014) Gross pathological lesions of bovine tuberculosis and efficiency of meat inspection procedure to detect-infected cattle in Adama municipal abattoir. J Vet Med Anim Health 6(2): 48-53.

32. De Lisle GW, Bengis RG, Schmitt SM, O Brien DJ (2002) Tuberculosis in free-ranging wildlife: detection, diagnosis and management. Rev Sci Tech 21(2): 317-334.

33. Desta F (2008) Study on mycobacterium bovis using conventional and molecular methods in cattle slaughtered in Kombolicha ELFORA meat processing plant. Thesis Addi Ababa University Ethiopia.

34. Diguimbaye Djaibe C, Hilty M, Ngandolo R, Mahamat HH, Pfyffer GE, et al. (2006) Mycobacterium bovis isolates from tuberculous lesions in Chadian zebu carcasses. Emerg Infect Dis 12(5): 769-771.

35. Ejeh EF, Markus IF, Ejeh AS, Musa JA, Lawan FA, et al. (2013) Seasonal prevalence of bovine tuberculosis lesion in cattle slaughtered in Yola abattoirs. Bangladsh J Vet Med 11(2): 113-120.

36. Fanlo P, Tiberio G (2007) Extrapulmonary tuberculosis. An Sist Sanit Navar 30(suppl 2): 143-162.

37. Firdessa R (2006) Preliminary study on bovine tuberculosis in and around Sululta town, North shoa zone of Oromia. Addis Ababa University Faculty of Vetrinary Medicin DVM thesis.

38. Firdessa R, Tschopp R, Wubete A, Sombo M, Hailu E, et al. (2012) High Prevalence of Bovine Tuberculosis in Dairy Cattle in Central Ethiopia: Implications for the Dairy Industry and Public Health. PLoS ONE 7(12).

39. Gagneux S, Small P (2007) Global phylogeography of tuberculosis and implications for tuberculosis product development. lancet Infect Dis 7(5): 328-337.

40. Gebremedhin G, Gebremedhin R, Gobena A (2014) Prevalence Study of Bovine Tuberculosis and Genus Typing of its Causative Agents in Cattle Slaughtered at Dilla Municipal Abattoir, Southern Ethiopia. Afr Basic Appl Sci 6(4): 103-109.

41. Glassroth J (2008) Pulmonary disease due to nontuberculous mycobacteria. Chest 133(1): 243-251.

42. Goodchild AV, Clifton Hadley RS (2001) Cattle-to-cattle transmission of Mycobacterium bovis. Tuberculosis 81(1-2): 23-41.

43. Gordon SV, Brosch R, Billault A, Garnier T, Eiglmeier K (1999) Identification of Variable Regions in the Genomes of Tubercle Bacilli Using Bacterial Artificial Chromosome Arrays. Mol Microbiol 32(3): 643-655.

44. Grange JM, Malcolm DY, Isabel N (1996) Guidelines for speciation within the Mycobacterium tuberculosis complex. 2nd ed. World Health Organization.

45. Tigre W, Gudeta T, Regassa F (2008) Preliminary study on bovine tuberculosis in Nekemte municipality abattoir, Western Ethiopia College of agriculture and School of Veterinary Medicine Jimma Ethiopia 58(3): 300-303.

46. Haddad N, Masselot M, Durand B (2004) Molecular differentiation of Mycobacter-ium bovis isolates. Review of main techniques and applications. Res Vet Sci 76(1): 1-18.

47. Hailemariam S (1975) A brief analysis of activities of meat inspection and quarantine division. Department of Veterinary Service Ministry of Agriculture Addis Ababa Ethiopia.

48. Hewinson RG, Vordermeier HM, Smith N, Gordon SV (2006) Recent advances in our knowledge of Mycobacterium bovis: a feeling for the organism. Vet Microbiol 112(2-4): 127-139.

49. Hlokwe TM, Van Helden P, Michel A (2013) Evaluation of the Discriminatory Power of Variable Number of Tandem Repeat Typing of Mycobacterium bovis Isolates from Southern Africa. Tran Emerg Dis 60(suppl 1): 111-120.

50. Kamerbeek J, Schouls L, Kolk A, Van Agderveld M, Van Soolingen D, et al. (1997) Simultaneous detection and strain differentiation of
Mycobacterium tuberculosis for diagnosis and epidemiology. J Clin Microbiol 35(4): 907-914.

51. Kidane D, Olobo JO, Habte A, Negesse Y, Aseffa A, et al. (2002) Identification of the causative organism of tuberculous lymphadenitis in Ethiopia by PCR. J Clin Microbiol 40(11): 4230-4234.

52. Mamo G, Abebe F, Worku Y, Hussein N, Legesse M, et al. (2013) Bovine tuberculosis and its associated risk factors in pastoral and agro-pastoral cattle herds of Afar Region, Northeast Ethiopia. J Vet Med Anim Health, 6: 171-179.

53. Marais BJ (2008) Tuberculosis in children. Pediatr Pulm 43: 322-329.

54. Mbugi EV, Katale BZ, Kendall S, Good L, Kibiki GS, et al. (2012) Tuberculosis cross-species transmission in Tanzania: Towards a OneHealth concept. Onderstepoort J Vet 79(2): 1-6.

55. Mekibeb A, Fulasa TT, Firdessa R, Hailu E (2013) Prevalence study on bovine tuberculosis and molecular characterization of its causative agents in cattle slaughtered at Addis Ababa municipal abattoir, Central Ethiopia. Trop Anim Health Pro 45(3): 763-769.

56. Menzies FD, Neill SD (2000) Cattle to cattle transmission of bovine tuberculosis. Vet J 160(2 ): 92-106.

57. Miliano suazo F, Salmar MD, Ramirez C, Payeur JB, Rhyan SC, et al. (2000) Identification of TB in cattle slaughtered in Mexico. Am J Vet Res 61(1): 86-89.

58. Müller B, Steiner B, Bonfoh B, Fané A, Smith NH, et al. (2008) Molecular characterisation of Mycobacterium bovis isolated from cattle slaughtered at the Bamako abattoir in Mali. BMC Vet Res 4: 26.

59. Müller B, Dürr S, Alonso S, Hattendorf J, Laisse CJ, et al. (2013) Zoonotic Mycobacterium bovis induced Tuberculosis in Humans. Emerg Infec Dis 19(6): 899-908.

60. Neill SD, O Brien J, Hanna J (1991) A mathematical model for Mycobacterium bovis excretion from tuberculous cattle. Vet Microbiol 28(1): 103-109.

61. Neill SD, Pollock JM, Bryson DB, Hanna J (1994) Pathogenesis of M. bovis infections in cattle. Vet Microbiol 40(1-2): 41-52.

62. Nemomsa B, Gebrezgabeher G, Birhanu T, Tadesse G, Getachew B (2014) Epidemiology of bovine tuberculosis in Butajira, southern Ethiopia. A cross sectional abattoir based study. AJMBR 8(33): 3112-3117.

63. (2009) Bovine Tuberculosis. OIE terrestrial manual. Paris p. 1-16.

64. (2010) Bovine tuberculosis. In: Manual of Diagnostic Tests and Vaccines for Terrestrial Animals 2019. World Organization for Animal Health pp. 683-698.

65.Pal M, Zenebe N, Rahman MT (2014) Growing significance of Mycobacterium bovis in human and health. Microbes Health,3(1): 2934.

66. Phillips CJ, Foster CR, Morris PA Teverson R (2003) The transmission of Mycobacterium bovis infection to cattle. Res Vet Sci 74(1): 1-15.

67. Pritchard DG (1988) A century of bovine tuberculosis, 1888-1988: conquest and controversy. J Comp Pathol 99(4): 357-399.

68. Quinn P J, Carter ME, Markey B, Carter GR (1999) Mycobacterium species. In: clinical veterinary microbiology. London Philadelphia pp. 157-170.

69. Radostits OM, Blood DC, Gay CC (1994) Diseases caused by Mycobacterium. In: veterinary medicine, a text book of disease of cattle, sheep, pigs, goats and horses. 8th ed London Baillieretindu 748-785.

70. Radostits OM, Gay CC, Hinchelift KW, Constabel PD (2006). Veterinary Medicine. A textbook of the disease of cattle, sheep, pig, goat and horses. 10th ed Elsevier 2065.

71. Regassa A (1999) Preliminary study on bovine tuberculosis in WolaitaSodo, South Ethiopia. DVM Thesis Addis Ababa University Ethiopia. 
72. Regassa A, Tassew A, Amenu K, Megersa B, Abuna F, et al. (2010) Across sectional study on bovine tuberculosis in Hawassa town and its surroundings, Southern Ethiopia. Trop Anim Health Pro 42: 915-920.

73. Rock RB, Olin M, Baker CA, Molitor TW, Peterson PK (2008) Central nervous system tuberculosis: pathogenesis and clinical aspects. Clin Microbiol Rev 21(2): 243-261.

74. Romha G, Ameni G, Berhe G, Mamo G (2013) Epidemiology of Mycobacterial infections in cattle in two districts of Western Tigray Zone, Northern Ethiopia. AFJMBR 7: 4031-4038.

75. Russel DG (2003) Highlighting the parallels between human and animal tuberculosis. J Vet Med edu 30(2): 140-142.

76. Sachdeva R, Gadre DV, Talwar V (2002) Characterisation and drug susceptibility patterns of extrapulmonary mycobacterial isolates. Indian J Med Res 115: 102-107.

77. Scarparo C, Piccoli P, Rigon A, Ruggiero G, Nista D, et al. (2001) Direct identification of mycobacteria from MB/BacT alert 3D bottles: comparative evaluation of two commercial probe assays. J Clin Microbiol 39(9): 3222-3227.

78. Shimeles SB (2008) Bovine tuberculosis: Epidemiologic aspects and public health implications in and around Debre Birihan. MSc thesis Ethiopia.

79. Shitaye JE, Getahun B, Alemayehu T, Skoric M, Treml F, et al. (2006) A prevalence study of bovine tuberculosis by using abattoir meat inspection and tuberculin skin testing data, histopathological and IS6110 PCR examination of tissues with tuberculous lesions in cattle in Ethiopia. Vet Med 51(11): 512-522.

80. Shitaye JE, Tsegaye W, Pavlik I (2007) Bovine tuberculosis infection in animal and human populations in Ethiopia: A review. Vet Med 8: 317 332.

81. Smith NH, Gordon S, Dela RR, Clifton Hadley RS, Hewinson RG (2006) Bottlenecks and broomsticks: the molecular evolution of Mycobacterium bovis. Nat Rev Microbiol 4(9): 670-681.

\section{ISSN: 2574-1241}

DOI: 10.26717/BJSTR.2020.24.004074

Yibrah Tekle. Biomed J Sci \& Tech Res

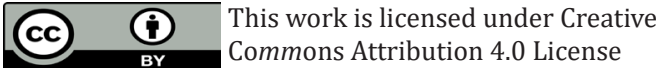

Submission Link: https://biomedres.us/submit-manuscript.php
82. Stout JE (2006) Evaluation and management of patient withpulmonary nontuberculous mycobacterial infections. Rev Anti Infect Ther 4(6): 981-993.

83. Teklu A, Asseged B, Yimer E, Gebeyehu M, Woldesenbet Z (2004) Tuberculous lesions not detected by routine abattoir inspection: the experience of the Hossana municipal abattoir, Southern Ethiopia. Rev Sci Tech 23(3): 957-964.

84. Thoen CO, Lobue PA, Enarson DA, Kaneene JB, De Kantor IN (2009) Tuberculosis: a re-emerging disease in animals and humans. Vet Ital 45(1): 135-181.

85. Thrusfield MV (2007) Veterinary epidemiology. $3^{\text {rd }}$ Ed Blackwell Science pp. 229-250.

86. Tigre W, Alemayehu G, Abetu T, Ameni G (2012) Preliminary study on the epidemiology of bovine tuberculosis in Jimma town and its surroundings, Southwestern Ethiopia. Afr J Microbiol Res 6(11): 25912597.

87. Watterson SA, Wilson SM, Yates MD, Drobniewski FA (1998) Comparison of three molecular assays for a rapid detection of rifampin resistance in Mycobacterium tuberculosis. J Clin Microbiol 36(7): 1969-1973.

88. Whipple LD, Boline AC, Miller MJ (1996) Distribution of lesion in cattle infected with Mycobacterium bovis. J Vet Diagn Invest 8(3): 351-354.

89. (2012) Global Tuberculosis Report 2012. World Health Organization $1-272$

90. Woyessa M, Jibril Y, Ameni G, Duguma R (2014) Molecular Epidemiology of Mycobacterium Tuberculosis Complex at Nekemte Municipality Abattoir, Weste-rn Ethiopia. Sci Tech Arts Res 3(2): 167-173.

91. Zeru F, Romha G, Ameni G (2013) Gross and Molecular Characterization of Mycobacterium tubercullosis Complex in Mekelle Town Municipal Abattoir, Northern Ethiopia. Glob Vet 11(5): 541-546.

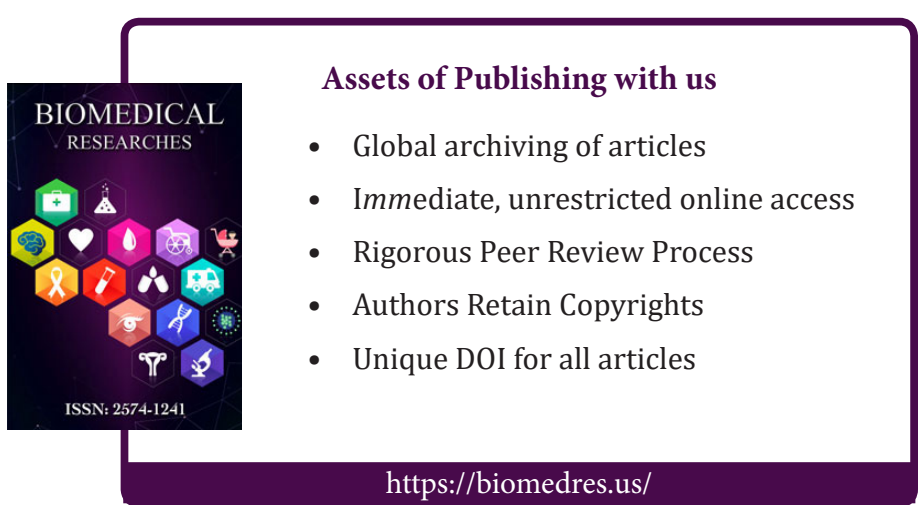

